\title{
Contraceptives utilization and barriers in Karnataka, Southern India: A survey on women residing in slums
}

\author{
Sowmya ${ }^{\mathrm{a}}$, Ansuya ${ }^{\mathrm{b}, *}, \mathrm{~V}$. Vinish ${ }^{\mathrm{b}}$ \\ ${ }^{a}$ Manipal College of Nursing Manipal, Manipal Academy of Higher Education, Manipal, Udupi District, Karnataka, 576104, India \\ ${ }^{\mathrm{b}}$ Department of Community Health Nursing, Manipal College of Nursing Manipal, Manipal Academy of Higher Education, Manipal, Udupi District, Karnataka, 576104, \\ India
}

\section{A R T I C L E I N F O}

\section{Keywords:}

Contraceptives

Utilization

Barriers

Married women

Slum

\begin{abstract}
A B S T R A C T
Background: Population explosion remains a major cause of concern in India. Although, the country became the first to implement a national population control programme in 1952, it is yet to effectively control its population growth.

Methods: A community-based cross-sectional survey was conducted to assess the utilization and barriers for nonutilization of contraceptives among slum resident married women of Udupi district, Karnataka, India between October 2017 to July 2018 The survey involved 323 married women aged 18-45 years. Data were generated using self-developed and validated questionnaire. Generated data were analyzed using descriptive analysis.

Results: The result of the study showed low utilization of contraceptives at $38.7 \%$. Leading barriers for nonutilization are fear of side effects (65.2\%), followed by desire for girl/boy child (31.3\%), husbands' disapproval (25.8\%), followed by $17.7 \%$ no family support (in-laws), lack of knowledge about contraceptive methods (25.3\%), and lack of personal interest to use contraceptives $(23.2 \%)$. The most frequently used method was tubectomy (73.6\%). Copper $\mathrm{T}(14.4 \%)$ and male condom $(8.0 \%)$ were predominant method among the temporary family planning methods used by the study population.

Conclusions: The low contraceptive rate might be attributed by fear of side effects, desire for girl/boy child, husbands' and family (in-law) disapproval, lack of knowledge about contraceptive methods and lack of motivation to use. Education, encouragement of health education programs and involvement of the spouse and inlaws might promote contraceptive utilization in slum dwellers.
\end{abstract}

\section{Introduction}

One of the major problems developing countries confront with is the increasing growth of population which in fact is a serious threat for the global community. ${ }^{1}$ In India, population explosion is a major problem since independence and it occupies $2.41 \%$ of the world's land area but supports over $18 \%$ of the world's population. The global population stands today at over 6 billion, one-sixth of which is in India. ${ }^{1}$ In 1921, the population of India was only 25.1 crores which is increased to 84.4 cores in 1991, 102.7 crores in $2001 .^{2}$ As per 2011 census India population 121 cores with a decadal growth of $17.65 \%$. Unite Nations (2015), the estimated population of India will be 1419 million approximately whereas China's population will be approximately 1409 million, by 2022. Uncontrolled population growth is recognized as the single most important impediment to the national development. ${ }^{3,4}$

India is the first country in the world to implement the family planning programme in the year 1952. But the country is still struggling to control population growth and stood the 2nd place and could surpass that of China's around 2024. ${ }^{3,4}$ Considerable efforts made by the Government on family planning programmes. A lot of efforts and resources have gone into the National Family Welfare Programme but the returns are not commensurate with the inputs. In India family planning services are integrated into reproductive and child health services at all levels of the health care delivery system and services has been provided to rural and urban communities at the health centre through health workers and the commodities are free of charge. ${ }^{5}$ Despite all these and several improvement programmes for reproductive mothers in India, there is no much improvement in contraceptives utilization among women and also increase in population growth. National Health and Family Survey3 conducted in the year 2005-2006. It revealed 53.5\% of married women are presently using any methods of contraceptives. ${ }^{6}$ The fourth survey was conducted after 10 years (2015-16), revealed that, $56.3 \% \%$

\footnotetext{
* Corresponding author.

E-mail address: ansuya.bengre@gmail.com (Ansuya).
} 
of married women are using contraceptives in India (NFHS-4, 201516). ${ }^{7}$ Study reported from Karnataka, the prevalence rate of contraceptive utilization was $44.3 \%{ }^{8}$ and $53 \%{ }^{9}$

Even though various measures have been taken to encourage the usage of contraception but, the achievement in this field was not to the extent expected. Unmet need for family planning and unintended pregnancy remain persistently high, suggesting underlying barriers to effective contraception. ${ }^{10}$

Several studies have been done among rural and urban women. But less studies done on contraceptives utilization among slum dwellers. Slum dwellers cannot be treated as a homogenous group in relation to their use of family planning services and the barriers faced in service utilization. The coastal districts of Karnataka, India have been attracting migrant workers for decades and majority of these migrant workers reside in slums. Udupi district, Karnataka has 17 slums and population approximately 7300 . To determine the extent of contraceptives usage and barriers for not using the contraceptives among slum women, this study has been undertaken.

\section{Methods}

\subsection{Study participants}

A community-based descriptive study was conducted from January to February 2018 in slums of Udupi district, Karnataka, India. The study participants consisted of married women of reproductive age group between 18 and 45 years sexually active residing in the slums of Udupi taluk were included in the study. Women who were divorced or not staying with husband/partner (not sexually involved), pregnant women, those who had undergone hysterectomy or attained menopause were excluded.

Sample and Sampling technique: A total of 323 married women in the age group of 18-45 years were included in the study. For the household survey, a multistage sampling technique was employed to locate the slums and samples. In the first stage, Udupi taluk was selected randomly from Udupi district, Karnataka state. In the second stage, five slums were selected using chit method from the list of slums belongs Udupi taluk. In the third stage list of households were used which was obtained from the municipality office. The required numbers of samples were selected using purposive sampling technique from the chosen slums based on eligibility criteria. In a case where two or more eligible women were encountered in the same household, only one woman was considered in the study at random to avoid intra-class correlation.

\section{Ethical approval}

Formal administrative written permission was obtained from the District Health Officer, Udupi district. Ethical clearance for the study was obtained from the Institutional Ethics Committee, Kasturba Hospital Manipal (IEC749/2017). Study was registered under Clinical Trials Registration- India (CTRI/2018/01/011572). Every eligible participant who was willing to participate, subject information sheet was provided and written informed consent was taken ahead to interview the women. Illiterate women have given the thumb impression in the consent form. Content was read by the researcher and made clear about the purpose of taking informed consent Participant's confidentiality and autonomy were respected during this study.

\subsection{Data collection instruments}

Validated, pre-tested questionnaire was used to collect the data. Questionnaire was adopted from different literatures and also considered the local situation of the study subjects. It was initially constructed in English language and it was validated by the experts from different discipline. The questionnaire comprised data on socio- demographic variables, present use of contraceptives, side-effects, past utilization and its side-effects (Section-A). In Section-B, barriers for non-utilization ie barriers from family, religious factors, availability of contraceptives, side-effects, and knowledge factors. Reliability of the tool was determined by test-retest method. Reliability co-efficient was calculated by rank order correlation. The reliability coefficient was 0.98. Then tools were translated to Kannada language (local language), then retranslated to English to check the language validity.

\subsection{Procedure for data collection}

The study period was from October 2017 to July 2018. Researcher visited slums and house to house survey was carried out. Located the house and enquired the availability of the women. Assessed for the eligibility to participate in the study as predetermined. Explained the purpose of the visit and obtained informed consent from the participants. After obtaining informed consent the data was collected through face-to -face interview. Firstly, background information was collected using socio-demographic proforma. Then information on utilization of contraceptives in the past, current use of contraceptives was collected. The participants who answered not using contraceptives, barriers for non-utilization information was collected using questionnaire on barriers for non-utilization. Visited houses from the selected slums until the desired number of women required for the study. There was $100 \%$ response rate for the interview and all participants were sexually active. In the slum all couples are staying with their husband, children and inlaws, we did not get women with not sexually active.

\subsection{Data management and analysis}

The data were coded, entered and analyzed using Statistical Package for the Social Sciences (SPSS) for Windows version 16.0 Descriptive statistics such as frequency and percentage were used to describe the background information, identify the prevalence of utilization and barriers for non-utilization of contraceptives.

A total of three hundred twenty-three married women were successfully interviewed giving a response rate of $100 \%$. The interview on barriers for non-utilization of contraceptives was conducted to married women those who are not using any contraceptives.

The description of sample characteristics is depicted in Table 1.

The age of women in the study population was 18-24 years and $25-31$ years are in equal proportion (39\%). Majority $95.4 \%$ of women belongs to Hindu religion and both women and their husbands had primary education level. Regarding occupation of the women, 54.5\% are the unskilled worker and $43.7 \%$ are the homemaker. $47.5 \%$ of women expressed their monthly family income is $>₹ 15000$ (USD). $34.1 \%$ of women had two children, $29.5 \%$ were having more than two children. $41.2 \%$ are living in a joint family and remaining nuclear family. About $88.5 \%$ of the women had previous information about contraceptives. More than one third (47.4\%) had gained information about contraceptives from doctors, $23.5 \%$ from nurses, $10.5 \%$ from relatives and $3.4 \%$ from ASHA worker.

\subsection{Utilization of contraceptives}

Table 2 shows only $38.7 \%$ are using contraceptives presently. Among the women using contraceptives, $73.6 \%$ were sterilized (tubectomy), $14.4 \%$ are cited copper $\mathrm{T}$ and only one subject experiencing irregular menstrual cycle. Since our study aimed to understand the prevalence of utilization of contraceptives, did not attempt to ask multiple contraceptive usage in the past (see Table 3 ).

Of 323 women, 10 were used contraceptives in the past. Out of 10 women, most of them were used copper $\mathrm{T}$ and six were experienced side effects of contraceptives. Three women had vaginal bleeding, one woman expressed about weight gain and two have complained about the irregular menstrual cycle. 
Table 1

Frequency and percentage distribution of sample characteristics.

\begin{tabular}{|c|c|c|}
\hline Sample characteristics $(\mathrm{N}=323)$ & Frequency(f) & Percentage (\%) \\
\hline \multicolumn{3}{|l|}{ Age in years } \\
\hline $18-24$ & 127 & 39.3 \\
\hline $25-31$ & 129 & 39.9 \\
\hline $32-38$ & 53 & 16.4 \\
\hline 39-45 & 14 & 4.3 \\
\hline \multicolumn{3}{|l|}{ Religion } \\
\hline Hindu & 308 & 95.4 \\
\hline Christian & 1 & 0.3 \\
\hline Muslim & 14 & 4.3 \\
\hline \multicolumn{3}{|l|}{ Education status of women } \\
\hline Primary & 159 & 49.2 \\
\hline Secondary & 109 & 33.7 \\
\hline Pre University & 19 & 5.9 \\
\hline Graduation & 4 & 1.2 \\
\hline Illiterate & 32 & 9.9 \\
\hline \multicolumn{3}{|l|}{ Educational status of husband } \\
\hline Primary & 154 & 47.7 \\
\hline Secondary & 120 & 37.2 \\
\hline Pre University & 21 & 6.5 \\
\hline Graduation & 7 & 2.2 \\
\hline Post graduation & 1 & 3 \\
\hline Illiterate & 20 & 2 \\
\hline \multicolumn{3}{|l|}{ Occupation of women } \\
\hline Skilled & 6 & 1.9 \\
\hline Unskilled worker & 176 & 54.5 \\
\hline Home maker & 141 & 43.7 \\
\hline \multicolumn{3}{|l|}{ Occupation of men } \\
\hline Skilled worker & 8 & 2.5 \\
\hline Unskilled worker & 315 & 97.5 \\
\hline \multicolumn{3}{|l|}{ Monthly income (INR/USD) } \\
\hline$<5000(<69$ USD $)$ & 1 & 3 \\
\hline 5001 (70 UDS -10000 (137 USD) & 95 & 29.4 \\
\hline $10001(138$ USD) - 15000(206 USD) & 65 & 20.1 \\
\hline$>15000$ (> 207 USD) & 162 & 47.5 \\
\hline \multicolumn{3}{|l|}{ Duration of marriage } \\
\hline $0-5$ years & 112 & 34.7 \\
\hline $6-10$ years & 126 & 39.0 \\
\hline $11-15$ years & 51 & 15.8 \\
\hline$>15$ years & 34 & 10.5 \\
\hline \multicolumn{3}{|l|}{ Number if living children } \\
\hline Nil & 11 & 3.3 \\
\hline One & 107 & 33.1 \\
\hline Two & 110 & 34.1 \\
\hline Three and more & 95 & 29.2 \\
\hline
\end{tabular}

\subsection{Barriers for non-utilization of contraceptives}

Leading barriers for non-utilization are fear of side effects (65.2\%), desire for girl/boy child $31.3 \%$, and $25.8 \%$ women expressed husbands' disapproval to non-use of contraceptive. About one-fourth expressed, not having much knowledge the safe use of contraceptives (25.3\%) and lack of personal interest to use contraceptives (23.2\%). 19.2\% of women opined that the use of contraception was against religion and $17.7 \%$ of them did not have much support from family members to adopt family planning methods. The reason for the reluctance of the husband $(13.1 \%)$ to use contraceptive since it induces discomfort and $(11.6 \%)$ of women had discomfort to use contraceptives. Few $(6.6 \%)$ women expressed that cost of contraceptive is high and most importantly there was lack of privacy to use contractive was (4.5\%). Few women expressed the reason for not using as they experienced side effects previously, difficult to use contraceptives, family planning center is far to get contraceptives and inadequate supply of contraceptives in the health center, some of felt it reduces the sexual pleasure.

\section{Discussion}

India suffers from the problem of overpopulation and current fertility rate as of 2015 , is 2.4 births per woman. Although the fertility rate in India has been declining, it has not reached the average replacement
Table 2

Frequency and percentage distribution of utilization of contraceptives by the married women.

\begin{tabular}{|c|c|c|}
\hline $\begin{array}{l}\text { Utilization of contraceptives } \\
(\mathrm{N}=323)\end{array}$ & Frequency (f) & Percentage (\%) \\
\hline \multicolumn{3}{|c|}{ Presently are you using any form of contraceptives? } \\
\hline Yes & 125 & 38.7 \\
\hline No & 198 & 61.3 \\
\hline \multicolumn{3}{|c|}{ If yes, name of the contraceptive $n=(125)$} \\
\hline Tubectomy & 92 & 73.6 \\
\hline Copper $\mathrm{T}$ & 18 & 14.4 \\
\hline Condom & 10 & 8.0 \\
\hline Contraceptive pill & 0 & 0.0 \\
\hline Injectable contraceptives & 5 & 4.0 \\
\hline \multicolumn{3}{|c|}{ Do you experience any problem due to use of contraceptives? $(n=125)$} \\
\hline Yes & 1 & 0.3 \\
\hline No & 124 & 99.7 \\
\hline \multicolumn{3}{|l|}{ If yes, specify $(n=1)$} \\
\hline Menstrual irregularities & 1 & 100 \\
\hline \multicolumn{3}{|c|}{ Have you used any contraceptives in the past? $(\mathrm{N}=323)$} \\
\hline Yes & 10 & 3.1 \\
\hline No & 313 & 96.9 \\
\hline \multicolumn{3}{|c|}{ If yes, name of the contraceptive $(n=10)$} \\
\hline Copper $\mathrm{T}$ & 6 & 60 \\
\hline Contraceptive pill & 2 & 20 \\
\hline Inject able contraceptives & 1 & 10 \\
\hline Condom & 1 & 10 \\
\hline \multicolumn{3}{|c|}{$\begin{array}{l}\text { Do you experience any problem due to past utilization of contraceptives? } \\
(n=10)\end{array}$} \\
\hline Yes & 6 & 60 \\
\hline No & 4 & 40 \\
\hline \multicolumn{3}{|l|}{ If yes, specify $(n=6)$} \\
\hline Vaginal bleeding & 3 & 50 \\
\hline Weight gain & 1 & 16.7 \\
\hline Irregular menstrual cycle & 2 & 33.3 \\
\hline
\end{tabular}

rate $_{\text {yet. }}{ }^{11}$

Contraception practice or family planning allows individuals and couples to anticipate and attain their desired number of children and the spacing and timing of their births. Family planning has a direct impact on population growth also women's health and well-being as well as on the consequence of each pregnancy. ${ }^{12}$

\subsection{Utilization of contraceptives}

In our study, the prevalence of contraceptives utilization among slum married women was low (38.7\%). The fourth national family health survey (NFHS-4) reported currently using contraception rate is $53.5 \%$ in India, $52.8 \%$ in Karnataka and $32.4 \%$ in Udupi district (201516). ${ }^{4}$ Several studies from Udupi district has reported the prevalence of use of contraceptives were low ie ranging between 40 and $45 \%{ }^{5-7,9}$ It revealed that the contraceptive utilization is less in Udupi district compared to the state and national level. And also it is evident that contraceptive usage among slum women is low comparatively general population in Udupi district.

The studies from the neighbor and other districts of Karnataka reported the utilization of contraceptives. The contraceptive utilization was reported by Manjeera et al. (2013) $71.2 \%$ in Mangaluru, ${ }^{13} 58.8 \%$ in Belgaum (Kruthika, 2017) ${ }^{14}, 70 \%$ in Vijayapur $(2016)^{15}, 75.2 \%$ in Anekal taluk, Bengaluru (George N, 2016). ${ }^{16}$ It shows the contraceptive utilization rate is higher in other districts compared to Udupi district. It can conclude that the contraceptive utilization rate among slum dweller (women) or general population is comparatively low to meet UN targets and vigorous awareness, motivation and encouragement is required to achieve the UN target and national goal of the country.

\subsection{Types of contraceptives used by the women}

In the present study majority women currently adopted tubectomy 
Table 3

Frequency and percentage of barrier for non utilization of contraceptives among married women.

\begin{tabular}{|c|c|c|}
\hline Barrier for non utilization $(\mathrm{N}=198)$ & Frequency (f) & Percentage (\%) \\
\hline \multicolumn{3}{|l|}{ Knowledge factors } \\
\hline Lack of knowledge about contraceptive methods. & 50 & 25.3 \\
\hline Does not have the knowledge about place of availability of contraceptive & 3 & 1.5 \\
\hline Contraceptives are difficult to use & 5 & 2.5 \\
\hline Health care professionals are not giving accurate information about availability of contraceptives & 2 & 1.0 \\
\hline Not aware about using appropriate contraceptive measures & 21 & 10.6 \\
\hline \multicolumn{3}{|l|}{ Family and religious factors } \\
\hline Religious beliefs & 38 & 19.2 \\
\hline Husband's disapproval for contraceptive use & 51 & 25.8 \\
\hline Desire for girl/boy child & 62 & 31.3 \\
\hline Family members does not support the use of contraceptives & 35 & 17.7 \\
\hline I am not comfortable to use contraceptives & 23 & 11.6 \\
\hline Husband is not comfortable with contraceptive use & 26 & 13.1 \\
\hline Lack of privacy hinders the use of contraceptives. & 9 & 4.5 \\
\hline \multicolumn{3}{|l|}{ Availability } \\
\hline Distance to family planning centre is more to get contraceptive & 4 & 2.0 \\
\hline Timing of health centre is inconvenient to get contraceptives & 4 & 2.0 \\
\hline The cost of contraceptives is very high & 13 & 6.6 \\
\hline No adequate supply of contraceptives in the health centre. & 2 & 1.0 \\
\hline \multicolumn{3}{|l|}{ Side effects } \\
\hline Fear of side effects & 129 & 65.2 \\
\hline I had side effects of contraceptives in the past & 7 & 3.5 \\
\hline Contraceptive use reduces sexual pleasure & 1 & 0.5 \\
\hline Lack of personal interest to use contraceptives & 46 & 23.2 \\
\hline
\end{tabular}

after two children or family completion (73.6\%) and remaining $26.4 \%$ are using temporary family planning methods. A supportive study was done in Pune, India reveals the utilization of permanent family planning method is more acceptable than temporary methods. ${ }^{17}$ Study finding from Africa reported female sterilization was zero percentage, ${ }^{18}$ it is really controversially.

Among the temporary contraceptive methods user (33, 26.4\%) 18 were using Copper T, followed by male condom 10 and injectable 5 . Surprisingly, among the study population, none of the women were practicing contraceptive pills and their counter partner did not adopt family planning method either temporary or permanent except condom. The majority opted for Copper $\mathrm{T}$ followed by condom use citing among slum women among temporary contraceptives. These findings are almost similar to Udupi district fact sheet. It was reported that female sterilization was $27 \%$ followed by IUD $1.7 \%$, condom $2.4 \%$, pills $0.4 \%$ and male sterilization $0 \%{ }^{19}$

Various national and international studies described the types of contraceptives used by the couple. A study conducted by Kamath et al., 2017 reported, $44.9 \%$ of the working women used copper $\mathrm{T}$ followed by rhythm method $23.7 \%$, male condom $13.2 \%$ pills $9.2 \%$ in Udupi district. ${ }^{20}$ Udgiri et al. (2017) claimed $68 \%$ of women using oral pills, tubectomy $76 \%$ followed by male condom $11.15 \%$ in Pune. ${ }^{17}$ Ashwini Nayak, Bangaluru, (2017) witnessed 59\% women and their partner using male condom, followed by $41 \%$ copper-T, $27 \%$ tubectomy, $18 \%$ pills, $10 \%$ injectable and $3 \%$ emergency contraception. Kruthika et al. (2017) claimed $16.0 \%$ of the women husbands' were using condom, $18.9 \%$ intrauterine device, $4.3 \%$ practicing rhythm method, $3.3 \%$ oral contraceptive pill and $16.3 \%$ of women were had sterilization. ${ }^{14}$

There is wide heterogeneity in the use of contraceptives across the country. Since family planning programs offer a wide range of methods and appropriate counselling, the couple uses different types of contraceptives, continuation and switching as per their convenience, comfort, and satisfaction.

\subsection{Barriers for non-utilization of contraceptives}

Barriers to contraception non-utilization is often described as a problem of access and interpreted as that women do not use contraceptives because they cannot find or afford them. While access is an issue, many other reasons have been cited by women for not using contraceptives, including lack of knowledge, cultural, personal, religious oppositions, health concerns, and fear of side effects. Therefore, just making contraceptives accessible does not guarantee that women will use them also required understanding the barriers for not using.

In the present study, among 323 women surveyed the higher proportion of women $(61.3 \%)$ were not using contraceptives. The study identified a number of reasons or barriers for not using contraceptives. The main reason for not using contraceptives among slum women was fear of side effects of contraceptives (65.2\%). About, $25.3 \%$ of the slum women described lack of knowledge about the contraceptive method. If anyone a has fear about treatment or practice the success rate of cure is questionable. Women's reasons for not using contraception have changed overtime. In the late 1980s a survey on women indicated that most were unaware of existing planning services. Now that response is uncommon. In our study it revealed that fear of side effects as the key factor for barriers to utilization of contraceptives. The fear regarding the side effects of contraceptive is very imperative. Now women and their partners are concerned about health and potential side effects. The fear of side effects could be due to lack of knowledge. Providing awareness, educating, counselling slum women, abolishing misconception about contraceptives could help to overcome this barrier. Health professionals, health care workers, and mass media would still need to do vigorous work on continuous providing knowledge and awareness about contraception.

Adopting family planning among couple is a collective decision. Husband's disapproval (25.8\%) was noteworthy among the barriers to use contraceptives in this study, followed by $17.7 \%$ no family support (in-laws) and husband not comfortable to use contraceptive. This result is corroborating other studies in India (Karnataka, UP) ${ }^{21,22}$ and Sudan. ${ }^{23}$ The link between husband's approval and presence of motherin-law in the household and lower uptake of contraception was reported by Pasha Omrana et al. ${ }^{24}$ in Pakistan. ${ }^{23}$ An opposition of husband's and in-laws to use contraceptives which deterred from adopting family planning methods. Spousal communication on these issues and joint participation in family planning education is required. Even today in our society husband -wife discussions about the sexual life are not considered to be appropriate. This finding provides evidence for the need of greater involvement of husbands' in contraception and other reproductive health and rights issues affecting their spouse and family. Family education regarding contraceptives needs to be emphasized 
rather women alone educating.

Usually in slums and villages, the number of children is decided after the birth of the first child. Sons are preferred over daughters by both husbands and wives. Family size and decisions about use of contraception often depend upon the sex of first child, with contraception being less likely if a boy has not been born. In our study also the barrier for the non-using contraceptives was intending to have more children was preference either boy/girl (31.3\%). Son preference is rooted in cultural traditions among slum population. Non-use of contraceptive methods may occur until the desired number of sons is achieved. Son preference is because, the boys are the heirs of the family name, property/wealth, and family voice in the community and not girls. Males are also responsible for parents as they age. Girls are expected to leave the family at marriage, and are thus viewed as having no significant contribution to the family. Couples are not using contraceptives nor do they do sterilization until they get a male child. Even mothers-inlaw may also mistreat their daughter-in-laws if they do not bear sons.

Under the National Health Mission, outreach to women in villages and urban slums to promote family planning has been undertaken. However, even in this context, some women are not fully acquiring family planning education; feel shy to discuss sexual issues or inadequate family planning methods with the health care provider.

\subsection{Strength of the study}

Interview technique was used to collect the data, so both illiterate and literate women were included in the study.

Random sampling technique was used to select the slums.

Sample size was decided by calculating the sample size using the formula.

\subsection{Limitation}

Sample were selected by purposive sampling to identify the women who meet inclusion criteria.

\section{Conclusion}

The prevalence of contraceptive use in this study was low. Proper counselling of women about possible side-effects of contraceptives would helpful to reduce misconception about contraceptives. And also need to include husbands and in-laws to the counselling to adopt family planning methods. Further research is required to explain misconception towards contraceptive to abolish barriers to use contraceptive use among this group of women.

\section{Declaration of competing interest}

The authors declare that they have no competing interests.

\section{Acknowledgement}

We would like to extend our deepest gratitude to the women who participated in the study.

\section{References}

1. Rastak L. Correlation between socio-demographic characteristics and contraceptive methods. Shahrekord Univ Med Sci J. 2005;7(2):21-28.

2. Growth of population in India. Available in http://www.economicsdiscussion.net/ population/growth-of-population-in-india-timeline-and-statistics/4487 Accessed on 01.08.2019.

3. China vs India population. http://statisticstimes.com/population/china-vs-indiapopulation.php.

4. Population of India. Available in http://factsanddetails.com/india/People_and_Life/ sub7_3a/entry-4139.html.

5. Phukhan Rumani S. Family Planning in India, its History, Programmes Importance Impact. 2014; 2014.

6. NFHS-3. International Institute for Population Sciences (IIPS) and Macro International. National Family Health Survey (NFHS-3). 2005; 200506.

7. NFHS-4. International Institute for Population Sciences (IIPS) and Macro International. National Family Health Survey (NFHS-3). 2015; 201516.

8. Aithal SK, Bairy M, Mayya S. Determinants of contraceptive usage among the slum dwelling migrant women in coastal Karnataka, India - a mixed methods study. Int $J$ Med Health Sci. 2016;2:63-74.

9. Sherpa SZ, Sheilini M, Nayak A. Knowledge, attitude, practice and preferences of contraceptive methods in Udupi district, Karnataka. J Fam Reprod Health. 2013;2:115-120.

10. Ministry of Health. National Family Health Survey-4 Reports. Ministry of Health and Family Welfare; 2016.

11. Bandhi G, Bhawnani D, Verma N, Soni GP. Assessment of contraceptive knowledge and practices among reproductive age group women in urban slums of Raipur city, Chhattisgarh,India. Natl J Community Med. 2014;4:349-354.

12. Sharma N, Deepthi SS, Mohan L, Jasleen K. Knowledge and practice of family planning among married women of reproductive age group in urban slums of Amritsar city. Int J Health Sci Res. 2015;2:42-48.

13. Manjeera LM, Rai NS. Contraceptive practices among reproductive age group of women in Justice K. S. Hegde Medical College Hospital, Mangalore. Int J Reprod Contracept Obstet Gynecol. 2013;2(1):39-46.

14. Kruthika K, Metgud CS. Knowledge score regarding contraceptive methods among married women in urban areas of Belagavi. Int J Community Med Public Health. 2017;4(4):1303-1306http://www.ijcmph.com.

15. Sindhu BM, Angadi MM. Knowledge, Attitude, and practice about family planning methods among reproductive age group women in a tertiary care institute. Int J Sci Stud. 2016;4(2):133-136.

16. George N, Sulekha T, Ramachandran A, Peters A, Kiran PR. The unmet needs for family planning and its associated factors among ever married women in selected villages of Anekal taluk, Karnataka: acommunity based cross sectional study. Int $J$ Community Med Public Health. 2018;5(5):2048-2052http://www.ijcmph.com.

17. Taklikar CS, More S, Kshirsagar V, Gode V. Prevalence of contraceptive practices in an urban slum of Pune city, India. Int J Med Sci Publ Health. 2015;4(12):172-177.

18. Akintade QL, Pengpid S, Peltzer K. Awareness and use of and barriers to family planning services among female university students in Lesotho. SAJOG. 2011;17(3)

19. National Family Health Survey-4. District Fact Sheet Udupi, Karnataka. International Institute for Population Sciences Mumbai; 2015-16http://rchiips.org/NFHS/FCTS/ KA/KA FactSheet 569 Udupi.pdfhttp://rchiips.org/NFHS/FCTS/KA/KA FactSheet 569_Udupi.pdfhttp://rchiips.org/NFHS/FCTS/KA/KA_FactSheet_569_Udupi.pdf.

20. Kamath P, Rao AP, Narayanan P. Contraceptive choices following first childbirth among working women in Udupi taluk. Clin Epidemiol Glob Health. 2017. https://doi. org/10.1016/j.cegh.2017.10.008.

21. Lekshmi AR, Manjula Ansuya. A study to assess the factors influencing unmet need of family planning among married women in selected villages of Udupi district, Karnataka. Nitte Univ J Health Sci. 2014;4(1):24-27.

22. Shaikh S, Dwivedi S. Predictors to use of family planning methods among women of Allahabad district, Uttar Pradesh. Health Popul Perspect Issues. 2014;37(4):118-127.

23. Abdalla AAA, Ahmmed EH. Evaluate use and barriers to accessing family planning services among reproductive age women in the White Nile, rural districts, Sudan. Health Sci J. 2017;11(6):1-5.

24. Pasha O, Goudar SS, Patel A, et al. Postpartum contraceptive use and unmet need for family planning in five low-income countries. Reprod Health. 2015;12(2)http://www. reproductive-health-journal.com/. 